\title{
Novel Glycosidic Linkage between Arabinogalactan and Peptidoglycan in the Cell Wall Skeleton of Nocardia rubra AN-115
}

\author{
By MAMORU FUJIOKA, * SHIGETAKA KODA AND \\ YUKIYOSHI MORIMOTO \\ Analytical Research Laboratories, Fujisawa Pharmaceutical Co., 2-1-6 Kashima, Yodogawa-ku, \\ Osaka 532, Japan
}

(Received 12 September 1984; revised 28 January 1985)

\begin{abstract}
A glycosidic linkage between the arabinogalactan and peptidoglycan has been demonstrated for the first time in cell walls from Nocardia rubra AN-115. Two oligosaccharides, Rha- $(1 \rightarrow 3)-$ GlcNAc and Gal-Rha-( $\rightarrow 3)$-GlcNAc, were identified by gas chromatography-mass spectrometry in acid hydrolysates of arabinogalactan containing defective peptidoglycan polymer obtained from stepwise alkaline degradations of $N$. rubra AN-115 walls. The arabinogalactan of $N$. rubra AN-115 walls contained not only Ara and Gal but also Rha, while peptidoglycan contained glycan polymers composed of GlcNAc-MurNGl units. These findings strongly suggest that arabinogalactan was linked glycosidically to peptidoglycan through a Rha-GlcNAc linkage in $N$. rubra AN-115 walls.
\end{abstract}

\section{INTRODUCTION}

Corynebacterium, Mycobacterium and Nocardia have similar cell wall structures, which consist of mycolic acid, arabinogalactan and peptidoglycan (Lederer, 1971; Michel \& Bordet, 1976; Barksdale \& $\mathrm{Kim}, 1977$ ). Arabinogalactan is a polysaccharide composed of D-arabinose and Dgalactose together with, in some cases, small amounts of neutral sugars such as mannose, glucose and rhamnose (Cummins, 1962; Yamaguchi, 1965; Abou-Zeid et al., 1982). The peptidoglycan comprises a glycan moiety composed of disaccharide units, $N$-acetyl-D-glucosaminyl- $N$-glycolyl (or -acetyl)-muramic acid and a tetrapeptide moiety composed of D- and L-alanine, D-glutamic acid and meso-diaminopimelic acid.

Mycolic acid is bound to the arabinose residue of arabinogalactan by an ester linkage, while the nature of the linkage between arabinogalactan and peptidoglycan remained unknown. Since Liu \& Gotschlich (1967) demonstrated the presence of a phosphodiester linkage between arabinogalactan and peptidoglycan by the isolation of a muramic acid 6-phosphate in walls of Mycobacterium butyricus, many studies have been made of the phosphodiester linkage in various bacterial walls (Kanetsuna, 1968; Cunto et al., 1969; Kotani et al., 1970). Muramic acid 6phosphate has been identified from $N$. rubra AN-115 walls by ${ }^{13} \mathrm{C}$ nuclear magnetic resonance studies, and suggests the presence of a phosphodiester linkage between the arabinogalactan and the peptidoglycan (A. Miyamae \& M. Shigi, unpublished results).

On the other hand, Kanetsuna \& San Blas (1970) reported that a glycosidic linkage between the $N$-acetyl-D-glucosamine residue of peptidoglycan and arabinogalactan in walls of Mycobacterium might be present in addition to the phosphodiester linkage. However, there has been insufficient evidence so far to show the presence of this glycosidic linkage.

\footnotetext{
Abbreviations: Ala, alanine; Ara, arabinose; CI, chemical ionization; Dap, diaminopimelic acid; EI, electron impact; Gal, galactose; GlcN, glucosamine; GlcNAc, $N$-acetylglucosamine; Glu, glutamic acid; Mur, muramic acid; MurNGl, $\mathrm{N}$-glycolylmuramic acid; Rha, rhamnose.
} 
We have found that alkaline treatment of $N$. rubra AN-115 walls liberated not only an arabinogalactan fraction but also large amounts of an additional polymer fraction composed of both arabinogalactan and peptidoglycan constituents. Since the phosphodiester linkage was readily broken by alkaline treatment, this finding indicates the presence of a further linkage between the arabinogalactan and the peptidoglycan besides the phosphodiester linkage.

The present report deals with a novel glycosidic linkage between the arabinogalactan and peptidoglycan in $N$. rubra AN-115.

\section{METHODS}

Organism and culture conditions. The walls were prepared from Nocardia rubra AN-115. This strain is preserved in the Research Laboratories of Fujisawa Pharmaceutical Co. It was grown in a medium containing the following: $10 \mathrm{~g}$ polypeptone, $5 \mathrm{~g}$ yeast extract and $1 \mathrm{~g}$ detergent (Adecanol; Asahi Denka Kogyo Co., Japan), in $800 \mathrm{ml}$ distilled water, adjusted to $\mathrm{pH} 7.0$ with $1 \mathrm{M}-\mathrm{NaOH}$. The cultures were incubated at $30^{\circ} \mathrm{C}$ on a rotary shaker at 220 r.p.m. for $3 \mathrm{~d}$ and then used to inoculate a medium containing $1.66 \mathrm{~kg}$ dextrose, $20.0 \mathrm{~kg}$ polypeptone, $10.0 \mathrm{~kg}$ yeast extract, $0.415 \mathrm{~kg} \mathrm{KH}_{2} \mathrm{PO}_{4}, 0.415 \mathrm{~kg} \mathrm{MgSO} 4.7 \mathrm{H}_{2} \mathrm{O}, 4.15 \mathrm{~kg}$ Adecanol and $760-7701$ distilled water, adjusted to $\mathrm{pH} 7.0$ with $50 \%(\mathrm{w} / \mathrm{v}) \mathrm{NaOH}$ solution, in a jar fermenter. The cells were cultured at $35 \pm 0.5^{\circ} \mathrm{C}$ for $90 \mathrm{~h}$ with mechanical stirring $\left(175 \pm 5\right.$ r.p.m.). After cooling to below $10^{\circ} \mathrm{C}$, the cells were harvested by centrifugation and washed with distilled water.

Preparation of cell walls. The cells were suspended in distilled water and disrupted mechanically in a mill (Dynomill type KDL; Willy A. Bachofen Manufacturing Engineers, Basel, Switzerland : 0.1 mm diameter glass beads were used). The disrupted cell suspension was mixed with $800 \mathrm{ml}$ Veronal buffer $\mathrm{pH} 7.5$ (572 mg Veronal, $375 \mathrm{mg}$ Veronal sodium, $27 \mathrm{mg} \mathrm{CaCl} .2 \mathrm{H}_{2} \mathrm{O}$ and $109 \mathrm{mg} \mathrm{MgSO}{ }_{4} .7 \mathrm{H}_{2} \mathrm{O}$, in $1000 \mathrm{ml}$ distilled water) containing $70 \mathrm{mg}$ deoxyribonuclease and $105 \mathrm{mg}$ ribonuclease and stirred at room temperature for $30 \mathrm{~min}$. The enzyme treated cell suspension was centrifuged at $1200 \mathrm{~g}$ for $15 \mathrm{~min}$. The supernatant fluid was centrifuged at $16950 \mathrm{~g}$ and the cell wall fraction was collected. This fraction was washed with acetone, $20 \%(\mathrm{v} / \mathrm{v})$ Triton X-100 solution and ethanol/distilled water $(2: 3, \mathrm{v} / \mathrm{v})$, successively. The residue was collected by centrifugation at $16950 \mathrm{~g}$, resuspended in distilled water, and the $\mathrm{pH}$ adjusted to 5.5 with $6 \mathrm{M}-\mathrm{HCl}$. After stirring for $60 \mathrm{~min}$, the suspension was centrifuged at $16950 \mathrm{~g}$ to obtain the crude cell walls. The walls were then incubated with $1.75 \mathrm{~g}$ protease (pronase; Kaken Kagaku Co., Japan) at room temperature for $24 \mathrm{~h}$ in Veronal/ $\mathrm{HCl}$ buffer $\mathrm{pH} 9.5$ [351 $0.1 \mathrm{M}$ Veronal sodium solution was adjusted to $\mathrm{pH} 9.5$ with $1 \mathrm{M}-\mathrm{HCl}$. The walls were sedimented at $16950 \mathrm{~g}$, washed with distilled water and 1,2-dichloroethane/ethanol $(1: 2, \mathrm{v} / \mathrm{v})$, and finally freeze-dried. This material was disrupted in a mill (Dyno-mill type KD5), passed through a sieve $(125 \mu \mathrm{m})$, and was designated as 'N-CWS'.

Isolation of arabinogalactan-peptidoglycan complex. About $30 \mathrm{~g} \mathrm{~N}-\mathrm{CWS}$ was hydrolysed with $1000 \mathrm{ml} 0.5 \%(\mathrm{w} / \mathrm{v})$ $\mathrm{KOH} /$ methanol solution at $37^{\circ} \mathrm{C}$ for $48 \mathrm{~h}$ under nitrogen. After neutralization with concentrated $\mathrm{HCl}$, the mixture was evaporated to a syrup, and then suspended in $50 \mathrm{ml}$ water. The suspension was extracted three times with $50 \mathrm{ml}$ ether. The residual suspension was filtered and washed with water, ethanol/ether $(1: 1, \mathrm{v} / \mathrm{v})$, chloroform and chloroform/methanol/water $(10: 10: 1$, by vol.) successively. The residue was resuspended in water and freezedried to yield the arabinogalactan-peptidoglycan complex $(22 \mathrm{~g})$.

Isolation of arabinogalactan containing defective peptidoglycan and arabinogalactan. The above freeze-dried material was hydrolysed with $600 \mathrm{ml} \mathrm{I} \mathrm{M-NaOH}$ at $70{ }^{\circ} \mathrm{C}$ for $24 \mathrm{~h}$ under nitrogen. After neutralization with acetic acid, the mixture was evaporated to a small volume and passed successively through filters $(3 \cdot 0,0.8$ and $0.45 \mu \mathrm{m}$ pore size). The filtrate from the latter filter was dialysed against water for $4 \mathrm{~d}$ and evaporated to a small volume. This solution was applied to a column of Dowex $50 \mathrm{~W} \mathrm{X8}\left(\mathrm{H}^{+} \mathrm{form}, 2.5 \times 15 \mathrm{~cm}\right)$, and eluted with $1000 \mathrm{ml}$ water. The eluate was again evaporated to a small volume and applied to a column of DEAE-cellulose DE $52\left(\mathrm{OH}^{-}\right.$form, $2.5 \times 15 \mathrm{~cm}$ ). The arabinogalactan fraction was eluted with $1000 \mathrm{ml}$ water and freeze-dried to yield $150 \mathrm{mg}$. The arabinogalactan containing the defective peptidoglycan fraction was eluted with $1500 \mathrm{ml} 0.01 \mathrm{M}$-phosphate buffer $(\mathrm{pH} 7 \cdot 0)$ and evaporated to a small volume. The solution was dialysed against water for $4 \mathrm{~d}$ and freeze-dried to yield $1.2 \mathrm{~g}$.

Analytical methods. Quantitative determinations of each constituent of the three polymers and N-CWS were performed by the following methods.

Lipids. The sample was hydrolysed with $5 \%(\mathrm{w} / \mathrm{v}) \mathrm{KOH} / \mathrm{methanol}$ solution at $100^{\circ} \mathrm{C}$ for $3 \mathrm{~h}$ in a sealed tube. The mixture was acidified with $1 \mathrm{M}-\mathrm{HCl}$ and extracted three times with ether. The combined extract was evaporated, dried over $\mathrm{P}_{2} \mathrm{O}_{5}$ in vacuo for $90 \mathrm{~min}$ at room temperature, and weighed.

Sugars. The sample was hydrolysed with $1 \mathrm{M}-\mathrm{HCl}$ at $90^{\circ} \mathrm{C}$ for $6 \mathrm{~h}$ in a sealed tube. The hydrolysate was applied to an ion-exchange column (Diaion WA 30, $\mathrm{OH}^{-}$form), and eluted with water, and evaporated to dryness. The residue was then dissolved in water and reduced with sodium borohydride for $1 \mathrm{~h}$. The solution was acidified with acetic acid and evaporated to dryness. Boric acid present in the residue was removed by co-distillation with methanol/ $\mathrm{HCl}(100: 1, \mathrm{v} / \mathrm{v})$ and methanol successively. The residue was treated with ethyl acetate/trifluoroacetic 
anhydride $(1: 0 \cdot 3, \mathrm{v} / \mathrm{v})$ for $30 \mathrm{~min}$. For gas chromatography, a sample of the solution was injected into a Shimadzu GC-7A instrument fitted with a $5 \%$ silicon XF-1105 on Gaschrom Q column $(3 \mathrm{~mm} \times 2 \mathrm{~m})$.

Amino sugars and amino acids. The sample was hydrolysed with $6 \mathrm{M}-\mathrm{HCl}$ at $100^{\circ} \mathrm{C}$ for $20 \mathrm{~h}$ in a sealed tube. The hydrolysate was evaporated to dryness and redissolved in $0.02 \mathrm{M}-\mathrm{HCl}$. A sample of the solution was injected into a Hitachi 835 amino acid analyser equipped with a Hitachi Custom ion-exchange resin no. 2617 column $(4 \mathrm{~mm} \times$ $25 \mathrm{~cm}$ ). Citrate buffers of pH 3.3, 4.3 and 4.9 were used stepwise for the eluents.

Phosphorus. The sample was pyrolysed in $\mathrm{HNO}_{3} / \mathrm{H}_{2} \mathrm{SO}_{4}(10: 3, \mathrm{v} / \mathrm{v})$ by wet combustion. After cooling, the solution was heated again with additional $\mathrm{HNO}_{3}$. The resulting phosphorus containing compound in the solution was converted to orthophosphoric acid by $\mathrm{H}_{2} \mathrm{O}_{2}$ and determined by the molybdenum-blue method (Boltz \& Lueck, 1958).

Losses on drying. These were determined after heating at $105^{\circ} \mathrm{C}$ for $5 \mathrm{~h}$.

Gas chromatography-mass spectrometry of arabinogalactan containing defective peptidoglycan. Arabinogalactan containing defective peptidoglycan (about $100 \mathrm{mg}$ ) was partially hydrolysed with $10 \mathrm{ml} 0.2 \mathrm{M}-\mathrm{H}_{2} \mathrm{SO}_{4}$ at $100{ }^{\circ} \mathrm{C}$ for $30 \mathrm{~min}$ in a sealed tube saturated with nitrogen. The hydrolysate was neutralized with barium carbonate, filtered and the filtrate was evaporated to dryness. The residue was dissolved in $20 \mathrm{ml}$ water and reduced with $200 \mathrm{mg}$ sodium borodeuteride. After acidification with acetic acid, the mixture was applied to a column of Dowex $50 \mathrm{~W} X 8$ $\left(\mathrm{H}^{+}\right.$form, $\left.2 \times 10 \mathrm{~cm}\right)$, and then eluted with $150 \mathrm{ml}$ water. The eluate was evaporated to dryness. Boric acid present in the residue was removed by co-distillation with methanol. The reduced product was dried over $\mathrm{P}_{2} \mathrm{O}_{5}$ in vacuo and then dissolved in $20 \mathrm{ml}$ dimethyl sulphoxide saturated with nitrogen gas. Methyl sulphinyl carbanion ( $1 \mathrm{ml})$ prepared by the reaction of sodium hydride and dimethyl sulphoxide (Hakomori, 1964) was added to the solution. The reaction mixture was stirred for $5 \mathrm{~h}$, and $1 \mathrm{ml}$ methyl iodide was added dropwise. The mixture was poured into $50 \mathrm{ml}$ water and extracted three times with $30 \mathrm{ml}$ chloroform. The combined chloroform extract was rinsed with water and evaporated to dryness. The methylated product was analysed by GC-MS. A Hitachi M-80 GC-MS instrument was used for electron impact (EI) study and a Finnigan $4000 \mathrm{GC}-\mathrm{MS}$ instrument with methane gas was used for chemical ionization (CI) study.

\section{RESULTS AND DISCUSSION}

The chemical compositions of N-CWS and the three polymers obtained are summarized in Table 1. The composition of N-CWS was very similar to that obtained from walls of other Nocardia reported by Azuma et al. $(1975,1976)$. This similarity allowed us to deduce that NCWS has a structure common to all walls from Nocardia, that is, a mycolic acidarabinogalactan-peptidoglycan complex having the following constituents: lipid, nocardomycolic acid; arabinogalactan, Ara, Gal, Rha $(2 \cdot 5: 1 \cdot 0: 0 \cdot 08$, by molar ratio); peptidoglycan, GlcN, Mur, Ala, Glu, Dap (1:1:2:1:1, by molar ratio) (Table 1).

$\mathrm{R}$ hamnose is one of the intrinsic constituents of arabinogalactan in N-CWS. The molar ratio of Rha to $\mathrm{Gal}$ in the three polymers as well as in N-CWS was almost always $0 \cdot 1: 1 \cdot 0$ (Table 1 ) in spite of some degradation occurring during the purification of the arabinogalactan from $\mathrm{N}$ CWS (see Methods).

In N-CWS, the content of phosphorus which was presumed to be present as muramic acid 6phosphate was about $0 \cdot 1 \%$. The molar ratio of phosphorus to muramic acid was about $1: 9$. The low phosphorus content suggested that even if all of the phosphorus was present in phosphodiester linkages between arabinogalactan and peptidoglycan, the number of linkages may not be sufficient to maintain binding between them. In addition, alkaline treatment of $\mathrm{N}$ CWS liberated lipid fractions from N-CWS, and gave an arabinogalactan-peptidoglycan complex. More severe alkaline treatment solubilized a fraction composed of both arabinogalactan and some peptidoglycan. This fraction appeared to be arabinogalactan linked to defective peptidoglycan judging from its composition (Table 1). It is noteworthy, however, that some peptidoglycan was still linked to arabinogalactan after such severe alkaline treatment. Peptide bonds in the peptidoglycan moiety were also hydrolysed by this treatment and we believe that all the phosphodiester linkages present between arabinogalactan and peptidoglycan would have been hydrolysed. On the other hand, the arabinogalactan itself did not contain any peptidoglycan components except for a very small amount of GlcN (Table 1). These results suggest that another type of linkage besides the phosphodiester linkage was present. Kanetsuna \& San Blas (1970) had reported that it might be a glycosidic linkage between a GlcN residue in 
Table 1. Chemical composition of $N-C W S$ and the three wall polymers

For N-CWS the mean values of five lots of samples are given. At least three determinations were made for each component tested in each sample. The values in parentheses are molar ratios. ND, No data; not detected.

\begin{tabular}{|c|c|c|c|c|}
\hline \multirow[b]{2}{*}{ Component } & \multicolumn{4}{|c|}{ Percentage dry weight of fraction } \\
\hline & $\mathrm{N}-\mathrm{CWS}$ & \multirow{2}{*}{$\begin{array}{c}\begin{array}{c}\text { Arabinogalactan- } \\
\text { peptidoglycan } \\
\text { complex }\end{array} \\
1 \cdot 2\end{array}$} & $\begin{array}{c}\text { Arabinogalactan } \\
\text { containing defective } \\
\text { peptidoglycan }\end{array}$ & Arabinogalactan \\
\hline Lipids & $27 \cdot 6$ & & ND & ND \\
\hline \multicolumn{5}{|l|}{ Sugars } \\
\hline Ára & $15 \cdot 2 \quad(2 \cdot 05)$ & $27.9(2 \cdot 22)$ & $41 \cdot 4 \quad(2 \cdot 60)$ & $67.9 \quad(2.54)$ \\
\hline Gal & $8.9 \quad(1.00)$ & $15 \cdot 1(1.00)$ & $19 \cdot 1 \quad(1 \cdot 00)$ & $32 \cdot 0 \quad(1 \cdot 00)$ \\
\hline Rha & $0 \cdot 9 \quad(0 \cdot 1)$ & $1 \cdot 3(0.09)$ & $1 \cdot 7 \quad(0 \cdot 10)$ & $2.4 \quad(0.08)$ \\
\hline \multicolumn{5}{|l|}{ Amino sugars } \\
\hline GlcN & $4.8 \quad(0.54)$ & $8.0(0.53)$ & $4.4 \quad(0.23)$ & $0.6 \quad(0.02)$ \\
\hline Mur & $6.2(0 \cdot 50)$ & $11 \cdot 3(0 \cdot 54)$ & $5 \cdot 2 \quad(0 \cdot 20)$ & $0.08(0.002)$ \\
\hline \multicolumn{5}{|l|}{ Amino acids } \\
\hline Ala & $8.5 \quad(1.94)$ & $8 \cdot 6(1 \cdot 15)$ & $2 \cdot 7 \quad(0 \cdot 29)$ & $0.03(0.002)$ \\
\hline Glu & $5.8 \quad(0.79)$ & $7 \cdot 3(0.59)$ & $2.2 \quad(0.14)$ & $0.03(0.001)$ \\
\hline Dap & $7 \cdot 2 \quad(0 \cdot 77)$ & $10 \cdot 4(0 \cdot 65)$ & $3 \cdot 3 \quad(0 \cdot 16)$ & $0.15(0.004)$ \\
\hline Gly & $1 \cdot 2$ & $0 \cdot 2$ & 0.03 & - \\
\hline Ser & $1 \cdot 7$ & $0 \cdot 1$ & 0.02 & - \\
\hline Thr & 1.4 & $0 \cdot 1$ & $0 \cdot 01$ & - \\
\hline Leu & $1 \cdot 2$ & $0 \cdot 2$ & $0 \cdot 01$ & - \\
\hline Phe & $1 \cdot 5$ & $0 \cdot 3$ & - & - \\
\hline Phosphorus & $0.09(0.06)$ & $0 \cdot 1(0 \cdot 04)$ & ND & ND \\
\hline Loss on drying & $7 \cdot 2$ & 11.9 & ND & ND \\
\hline
\end{tabular}

the peptidoglycan and the arabinogalactan. To investigate this possibility arabinogalactan containing defective peptidoglycan was partially hydrolysed and the occurrence of oligosaccharides containing both GlcN and constituents of arabinogalactan was studied by GC-MS.

Fig. 1 shows a total ion current chromatogram of the permethylated alditol derivatives of the oligosaccharides mixture obtained from the partial acid hydrolysis of arabinogalactan containing defective peptidoglycan. The oligosaccharide structures corresponding to each peak in Fig. 1 were identified by mass fragmentation analysis (Kärkkäinen, 1970, 1971 ; Lönngren \& Svensson, 1974; Lundblad et al., 1975; Mononen et al., 1978).

EI mass spectra for peaks $E$ and $I$ are shown in Figs 2 and 3 respectively.

The A-series fragments (Lönngren \& Svensson, 1974; Lundblad et al., 1975) $\mathrm{A}_{1}\left(\mathrm{~m} / z\right.$ 189), $\mathrm{A}_{2}$ $(m / z 157)$ and $A_{3}(m / z 125)$ and the fragment Ald $(m / z 277)$ show the sequence Rha-GlcNAc (Fig. 2). The presence of additional fragments such as $\mathbf{M}-45(\mathrm{~m} / z 437), \mathbf{M}-46(\mathrm{~m} / z 436)$, $M-89(m / z 393), M-133(m / z 349)$ and the fragment $m / z 131$ indicates that the linkage position between Rha and GlcNAc is $1 \rightarrow 3$.

In Fig. 3, the A-series fragments $\mathrm{aA}_{1}(m / z 219), \mathrm{aA}_{2}(m / z 187), \mathrm{aA}_{3}(m / z 155), \mathrm{baA}_{1}(m / z 393)$ and the J-series fragment (Lönngren \& Svensson, 1974; Lundblad et al., 1975) abAld J $(m / z 511)$ and the fragments Ald $(m / z 277)$ and bAld $(m / z 451)$ show the sequence Gal-Rha-GlcNAc. The presence of additional fragments such as $\mathrm{M}-45(\mathrm{~m} / \mathrm{z} 641), \mathbf{M}-46(\mathrm{~m} / \mathrm{z} 640), \mathbf{M}-89(\mathrm{~m} / \mathrm{z} 597)$ and $M-133(\mathrm{~m} / z 553)$, and the fragment $m / z 131$ indicated that the linkage position between Rha and GlcNAc was also $1 \rightarrow 3$, but the linkage position between $\mathrm{Gal}$ and $\mathrm{R}$ ha has not been determined.

In the case of EI mass studies, neither molecular ions of the permethylated alditol derivatives of Rha-( $(1 \rightarrow 3)$-GlcNAc nor Gal-Rha- $(1 \rightarrow 3)$-GlcNAc were identified, but CI mass spectra obtained using methane as a reagent gas clearly showed $\mathrm{M}+\mathrm{H}, \mathrm{M}+\mathrm{C}_{2} \mathrm{H}_{5}$ and $\mathrm{M}+\mathrm{C}_{3} \mathrm{H}_{5}$ ions of each oligosaccharide. The $m / z$ values and relative intensities $(\%)$ of the $\mathrm{CI}$ mass spectra of peaks $\mathrm{E}$ and I were: $\mathrm{M}+\mathrm{H}, 483(2 \cdot 1 \%) ; \mathrm{M}+\mathrm{C}_{2} \mathrm{H}_{5}, 511(13.7 \%) ; \mathrm{M}+\mathrm{C}_{3} \mathrm{H}_{5}, 523(4.6 \%)$ for peak $E$ and $M+H, 687(4.9 \%) ; M+C_{2} H_{5}, 715(12.5 \%) ; M+C_{3} H_{5}, 727(4.8 \%)$ for peak $I$. 


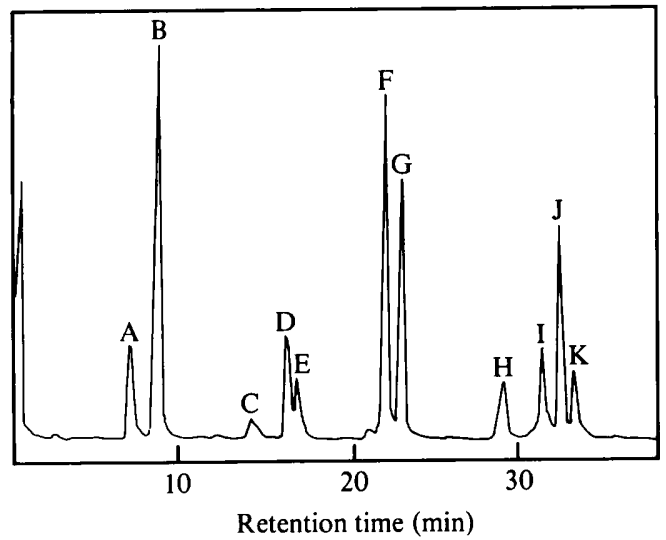

Fig. 1. Total ion current chromatogram of the permethylated alditol derivatives obtained from partial acid hydrolysis of arabinogalactan containing defective peptidoglycan. The conditions used were $2 \%$ $\mathrm{OV}-1$ on Gaschrom Q $(3 \mathrm{~mm} \times 100 \mathrm{~cm})$, injection temperature $285^{\circ} \mathrm{C}$, column temperature $180-$ $280^{\circ} \mathrm{C}$, ionizing voltage $20 \mathrm{eV}$, total emission current $100 \mu \mathrm{A}$. A and $\mathrm{B}$, permethylated alditol derivatives of arabinose dimers; $C$ and $D$, galactose dimers; $H$, galactose trimer; $J$ and $K$, arabinose tetramers.
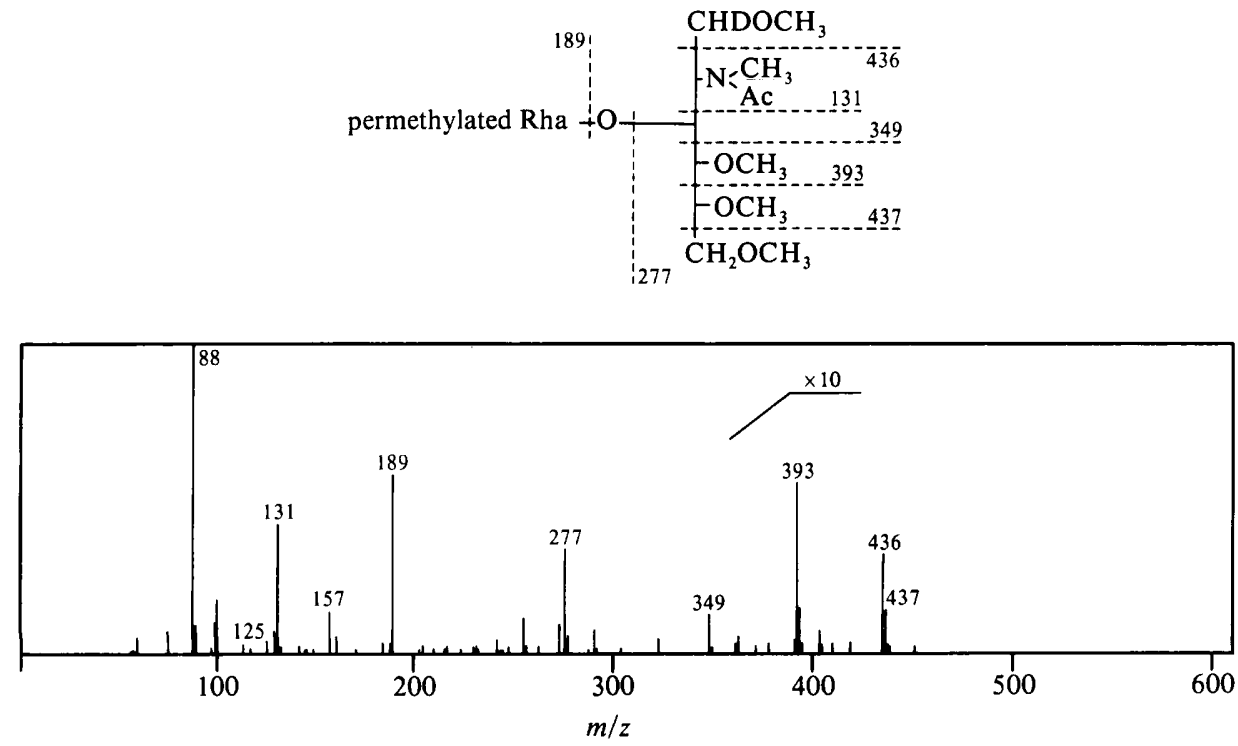

Fig. 2. Mass spectrum of peak E.

The GC-MS conditions were $1.5 \% \mathrm{OV}-1$ on Chromosorb W HP $(2 \mathrm{~mm} \times 70 \mathrm{~cm})$; injection temperature, $230^{\circ} \mathrm{C}$; column temperature, $180-280^{\circ} \mathrm{C}$; ionizing voltage, $70 \mathrm{ev}$; total emission current, $400 \mu \mathrm{A}$; reagent gas, methane 0.3 Torr $(40 \mathrm{~Pa})$.

As shown in Table 1 , both $\mathrm{Gal}$ and $\mathrm{Rha}$ were constituents of arabinogalactan whereas GlcNAc was a constituent of peptidoglycan. Thus, the presence of Rha-( $1 \rightarrow 3)$-GlcNAc and GalRha-(1 $\rightarrow 3)-G l c N A c$ strongly suggested that a novel glycosidic linkage existed between arabinogalactan and peptidoglycan in N-CWS. The proposed structure of the arabinogalactanpeptidoglycan moiety of N-CWS is illustrated in Fig. 4 together with the phosphodiester linkage between arabinogalactan and peptidoglycan. However, we could not identify any

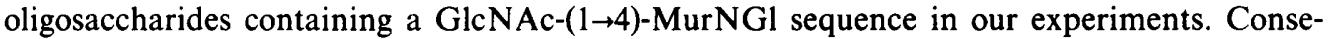
quently, some ambiguity still remains concerning the origin of GlcNAc in Rha-( $1 \rightarrow 3)$-GlcNAc 

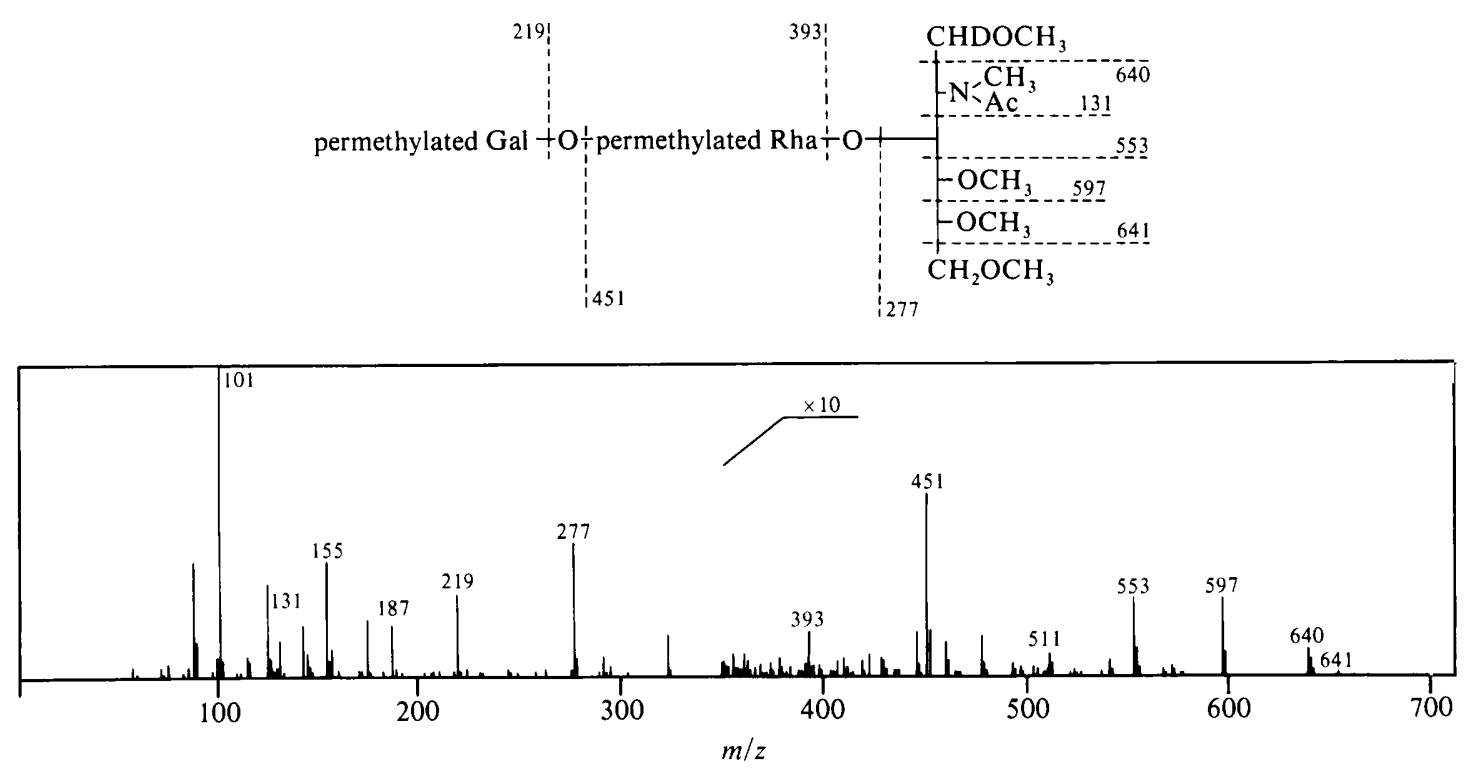

Fig. 3. Mass spectrum of peak I.

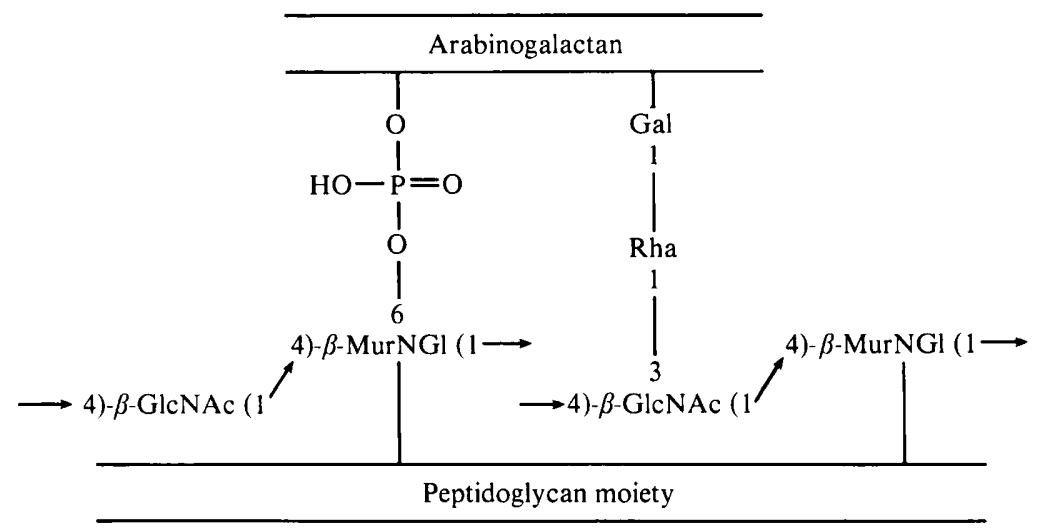

Fig. 4. Tentative structure of the arabinogalactan-peptidoglycan moiety in walls of Nocardia rubra AN-115.

and Gal-Rha-(1-3)-GlcNAc. A structure, such as arabinogalactan-Gal-Rha-GlcNAc-(?)peptidoglycan is possible whereby GIcNAc is part of the arabinogalactan rather than the peptidoglycan. However, it is more likely that the GlcNAc is derived from peptidoglycan for the following reasons. The linkage between GlcNAc and peptidoglycan seems to be glycosidic rather than a phosphodiester. If it were a phosphodiester linkage, it should have been hydrolysed along with most of the phosphodiester linkages during alkaline hydrolysis, and as a consequence, the molar ratio of Glc:Mur in the arabinogalactan containing defective peptidoglycan would be $>1$ not 1 (see Table 1 ). A ratio greater than 1.0 would be obtained if the GlcNAc was derived from the arabinogalactan.

We are grateful to Dr K. Noda and Mr Y. Miyao in the Central Research Laboratories of our company for the measurement of CI mass spectra. 


\section{REFERENCES}

Abou-Zeid, C., Voiland, A., Michel, G. \& Cocito, C. (1982). Structure of the wall polysaccharide isolated from a group of Corynebacteria. European Journal of Biochemistry 128, 363-370.

azuma, I., Kanetsuna, F., Taniyama, T., Yamamura, Y., Hori, M. \& Tanaka, Y. (1975). Adjuvant activity of mycobacterial fractions. I. Purification and in vivo adjuvant activity of cell wall skeletons of Myocohacterium boris BCG, Nocardia asteroides 131 and Corynebacterium diphtheriae PW8. Biken Journal 18, 1-13.

Azuma, I., Taniyama, T., Sugimura, K., Aladin, A. A. \& Yamamura, Y. (1976). Mitogenic activity of the cell walls of Mycobacteria, Nocardia, Corynebacteria and anaerobic coryneforms. Japanese Journal of Microbiology 20, 263-271.

BarkSDAle, L. \& KiM, K.-S. (1977). Mycobacterium. Bacteriological Revien's 41, 217-372.

Boltz, D. F. \& LUECK, C. H. (1958). Phosphorus. In Colorimetric Determination of Nonmetals, p. 29. Edited by D. F. Boltz. New York: Interscience.

Cummins, C. S. (1962). Chemical composition and antigenic structure of cell walls of Corynebacterium. Mycobacterium, Nocardia, Actinomyces and Arthrobacter. Journal of General Microbiology 28, 35-50.

Cunto, G., Kanetsuna, F. \& Imaeda, T. (1969). Chemical analysis of the mucopeptide of Mycobacterium smegmatis. Biochimica et biophy'sica acta 192 , $358-360$

HAKOMORI, S. (1964). A rapid permethylation of glycolipid and polysaccharide catalyzed by methyl sulfinyl carbanion in dimethyl sulfoxide. Journal of Biochemistry 55, 205-208.

KANETSUNA, F. (1968). Chemical analyses of mycobacterial cell walls. Biochimica et biophysica acta $\mathbf{1 5 8}$, 130-143.

Kanetsuna, F. \& San Blas, G. (1970). Chemical analysis of a mycolic acid-arabinogalactan-mucopeptide complex of mycobacterial cell wall. Biochimica et biophysica acta 208, 434-443.
KÄRKKÄINEN, J. (1970). Analysis of disaccharides as permethylated disaccharide alditols by gas-liquid chromatography-mass spectrometry. Carbohydrate Research 14, 27-33.

KäRKKÄINEN, J. (1971). Structural analysis of trisaccharides as permethylated trisaccharide alditols by gas-liquid chromatography-mass spectrometry. Carbohydrate Research 17, 11-18.

Kotani, S., Yanagida, I., Kato, K. \& Matsuda, T. (1970). Studies on peptides, glycopeptides and antigenic polysaccharide-glycopeptide complexes isolated from an L-11 enzyme lysate of the cell walls of Mycobacterium tuberculosis strain H37Rv. Biken Journal 13, 249-275.

LEDERER, E. (1971). The mycobacterial cell wall. Pure and Applied Chemistry 25, 135-165.

LiU, T.-Y. \& Gotschlich, E. (1967). Muramic acid phosphate as a component of the mucopeptide of gram-positive bacteria. Journal of Biological Chemistry 242, 471-476.

LönNGREN, J. \& Svensson, S. (1974). Mass spectrometry in structural analysis of natural carbohydrates. Advances in Carbohydrate Chemistry and Biochemistry 29, 41-106.

Lundblad, A., Masson, P. K., Norden, N. E., Svenssen, S. \& OCKerman, P. A. (1975). Determination of mannose-containing trisaccharide in the urine of patients and heterozygotes of mannosidosis. Biomedical Mass Spectrometry 2, 285-287.

Michel, G. \& BoRdeT, C. (1976). Cell wall of Nocardiae. In The Biology of the Nocardiae, pp. 141159. Edited by M. Goodfellow, G. M. Brownell \& J. A. Serrano. London: Academic Press.

Mononen, L., Finne, J. \& KärkKäInen, J. (1978). Analysis of permethylated hexopyranosyl-2-acetamide-2-deoxyhexitols by g.l.c.-m.s. Carbohydrate Research 60, 371-375.

YamaGuCHI, T. (1965). Comparison of the cell-wall composition of morphologically distinct actinomycetes. Journal of Bacteriology 89, 444-453. 